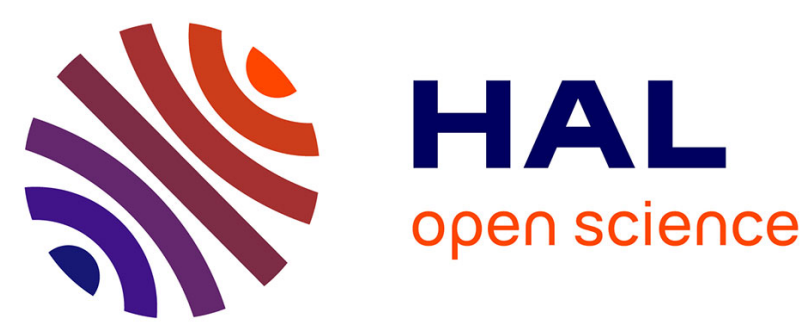

\title{
Combined Biochemical, Biophysical, and Cellular Methods to Study Fe-S Cluster Transfer and Cytosolic Aconitase Repair by MitoNEET
}

Cécile Mons, Ioana Ferecatu, Sylvie Riquier, Ewen Lescop, Cécile Bouton, Marie-Pierre Golinelli-Cohen

\section{To cite this version:}

Cécile Mons, Ioana Ferecatu, Sylvie Riquier, Ewen Lescop, Cécile Bouton, et al.. Combined Biochemical, Biophysical, and Cellular Methods to Study Fe-S Cluster Transfer and Cytosolic Aconitase Repair by MitoNEET. Methods in Enzymology, 2017, 595, pp.83-106. 10.1016/bs.mie.2017.07.010 . hal-01873518

\section{HAL Id: hal-01873518 \\ https://hal.science/hal-01873518}

Submitted on 26 Sep 2018

HAL is a multi-disciplinary open access archive for the deposit and dissemination of scientific research documents, whether they are published or not. The documents may come from teaching and research institutions in France or abroad, or from public or private research centers.
L'archive ouverte pluridisciplinaire HAL, est destinée au dépôt et à la diffusion de documents scientifiques de niveau recherche, publiés ou non, émanant des établissements d'enseignement et de recherche français ou étrangers, des laboratoires publics ou privés. 
Running title: Fe-S cluster transfer from mitoNEET

Combined biochemical, biophysical and cellular methods to study Fe$\mathrm{S}$ cluster transfer and cytosolic aconitase repair by mitoNEET.

Cécile Mons ${ }^{*}$, Ioana Ferecatu ${ }^{\text {}}$, Sylvie Riquier ${ }^{*}$, Ewen Lescop ${ }^{*}$, Cécile Bouton ${ }^{*}$, Marie-Pierre Golinelli-Cohen ${ }^{*}, 1$

* Institut de Chimie des Substances Naturelles (ICSN), CNRS UPR 2301, Univ. Paris-Sud, Université Paris-Saclay, 91190 Gif-sur-Yvette, France

Ж INSERM, UMR-S1139, Faculté des Sciences Pharmaceutiques et Biologiques, Université Paris Descartes, Sorbonne Paris Cité, 75006 Paris, France.

${ }^{1}$ Corresponding author: e-mail address: marie-pierre.golinelli@cnrs.fr

\section{Contents}

1. Introduction

2. In vitro $\mathrm{Fe}-\mathrm{S}$ cluster transfer from $\mathrm{mNT}$ to a model recipient

2.1. Purifications of $\mathrm{mNT}$ and FDX

2.1.1. Purification of Homo sapiens holo-mNT

2.1.2. Purification of E. coli holo-FDX

2.1.3. Preparation of apo-FDX

2.2. In vitro cluster transfer reaction between holo-mNT and apo-FDX

2.2.1. UV-visible absorption spectroscopy

2.2.2. Native PAGE

2.2.3. Nuclear magnetic resonance spectroscopy

3. Identification of a physiological recipient of the mNT cluster 


\title{
3.1. In vitro studies
}

3.1.1. In vitro cluster transfer reaction between holo-mNT and IRP1

3.1.2. Measurement of aconitase activity

\subsection{In cellulo studies}

3.2.1. Effect of NO challenge on cytosolic aconitase activity

\subsubsection{NO challenge assay}

3.2.1.2. Preparation of mitochondria-enriched fractions and cytosolic extracts

3.2.2. Involvement of $\mathrm{mNT}$ in the Fe-S cluster repair of cytosolic aconitase after nitrosative stress

3.3. Partner protein abundance in mammalian tissues
4. Conclusions
References

\begin{abstract}
MitoNEET is the first identified Fe-S protein anchored to mammalian outer mitochondrial membranes with the vast majority of the protein polypeptide located in the cytosol, including its $[2 \mathrm{Fe}-2 \mathrm{~S}]$-cluster binding domain. The coordination of the cluster is unusual and involves three cysteines and one histidine. MitoNEET is capable of transferring its redox active Fe-S cluster to a bacterial apo-ferredoxin in vitro even under aerobic conditions, unlike other Fe-S transfer proteins such as ISCU. This specificity suggests its possible involvement in Fe-S repair after oxidative and/or nitrosative stress. Recently, we identified cytosolic aconitase/Iron Regulatory Protein 1 (IRP1) as the first physiological protein acceptor of the mitoNEET Fe-S cluster in an Fe-S repair process. This chapter describes methods to study in vitro mitoNEET Fe-S cluster transfer/repair to a bacterial ferredoxin used as a model apo-receptor and in a
\end{abstract}


more comprehensive manner to cytosolic aconitase/IRP1 after a nitrosative stress using in vitro, in cellulo and in vivo methods.

\section{INTRODUCTION}

For the first time in 1978, the presence of a [2Fe-2S] protein in outer mitochondrial membranes (OMMs) from beef heart was detected by electronic paramagnetic resonance spectroscopy (Heidrich, Albracht, \& Backstrom, 1978). It was only in 2004 that this Fe-S protein, called mitoNEET ( $\mathrm{mNT})$, was isolated from rat liver mitochondria and shown to be a potential target of the type II diabetes drug pioglitazone (Colca et al., 2004). Biophysical and biochemical studies characterized $\mathrm{mNT}$ as a small homodimeric protein $(13 \mathrm{kDa}$ for each monomer), which assembles a $[2 \mathrm{Fe}-2 \mathrm{~S}]$ cluster per monomer. In mammalian cells, $\mathrm{mNT}$ is anchored to the OMM by its $\mathrm{N}$ terminus part (32 amino acids), with the vast majority of the protein located in the cytosol, including its Fe-S cluster binding domain (Wiley, Murphy, Ross, van der Geer, \& Dixon, 2007). This was the first identified Fe-S protein of the OMM. MNT belongs to the NEET protein family. Its members are characterized by the presence of at least one CDGSH iron-sulfur domain (CISD) motif ([C-X-C-X2-(S/T)-X3-P-X-C-D-G$(\mathrm{S} / \mathrm{A} / \mathrm{T})-\mathrm{H}])$ involved in the coordination of a [2Fe-2S] cluster by 3 cysteines (Cys-72, Cys74, and Cys-83 for Homo sapiens mNT) and one histidine (His-87 for Hs mNT) (Paddock et al., 2007; Wiley et al., 2007). Present in all kingdoms of life, this family is composed of only three members in mammals: mNT (CISD1), Miner1 (CISD2, ERIS, Noxp70 or NAF-1), and Miner2 (CISD3) (Inupakutika et al., 2017).

MNT is a cluster donor protein whose cellular function is linked to iron and ROS homeostasis (Tamir et al., 2015). Holo-mNT (i.e the form with the cluster) is capable of transferring in vitro its redox active Fe-S cluster to a bacterial apo-ferredoxin (FDX), an FDX that has lost its cluster (Zuris et al., 2011). In contrast to the strict anoxia required for other Fe-S transfer proteins such as ISCU, mNT is able to perform cluster transfer under 
aerobic conditions, suggesting its possible involvement in Fe-S repair after oxidative stress. Recently, we identified the cytosolic iron regulator, named cytosolic aconitase/Iron Regulatory Protein 1 (IRP1) as the first physiological protein acceptor of the $\mathrm{mNT}$ Fe-S cluster in an Fe-S cluster repair pathway (Ferecatu et al., 2014).

In a first part, this chapter describes methods to study $\mathrm{Fe}-\mathrm{S}$ cluster transfer/repair in vitro using E. coli FDX as model recipient protein. The UV-visible absorption spectroscopy allows following the evolution of holo-protein populations (holo-mNT vs holo-FDX) as well as the redox state of the cluster. With native PAGE and Nuclear Magnetic Resonance spectroscopy, the populations of protein species (holo- and apo-mNT, holo- and apo-FDX) are precisely quantified. In a second part, we will describe in cellulo methods to study the involvement of $\mathrm{mNT}$ in the repair of the Fe-S cluster of cytosolic aconitase after stress challenge. Finally, we will present protocols to check the expression of the two partners in animal tissues.

\section{In vitro $\mathrm{Fe}-\mathrm{S}$ cluster transfer from $\mathrm{mNT}$ to a model recipient}

The properties of the $\mathrm{mNT}$ cluster transfer reaction can be properly characterized in vitro using a model recipient apo-protein. This protein must (1) be easy to purify in large amounts; (2) have a UV-visible absorption spectrum and a native PAGE migration different from those of holo-mNT; (3) have native PAGE migrations that differ between the apo- and holo-forms; (4) have a holo-form that is stable over time. We used the [2Fe-2S]-containing E. coli FDX, which fulfills all these criteria. This protein is stable under aerobic conditions up to roughly 25-30 ${ }^{\circ} \mathrm{C}$. A hyperthermophilic FDX will be preferred for studies at higher temperatures. In section 2.1, we describe the purification of the two proteins (holo-mNT and apo-FDX) and three methods to study the cluster transfer reaction (Figure 1).

\subsection{Purifications of mNT and FDX}


The proteins are purified after overexpression in E. coli BL21 Star (DE3). For FDX, we have chosen to purify the holo-form, and then to remove the Fe-S cluster to obtain a homogeneous apo-FDX.

\section{Equipment and chemical products}

- Protease inhibitor SIGMA FAST EDTA free (Sigma)

- Cell disruptor: Constant Cell Disruption Systems (Constant Systems Ltd)

- $\quad$ Äkta Fast Protein Liquid Chromatography (FPLC) system (GE Healthcare)

\section{General considerations}

- All buffers for FPLC have to be $0.45 \mu \mathrm{m}$-filtered and flushed with nitrogen

- Cell lysates have to be $0.45 \mu \mathrm{m}$-filtered before loading on columns

- Purification of both proteins can be performed at room temperature. If a multiwavelength detector is used with FPLC, set it to $280 \mathrm{~nm}$ (polypeptide) and $460 \mathrm{~nm}$ (cluster)

- Proteins were concentrated by centrifugation using Amicon Ultra 15 mL 3K (Sigma) at $4{ }^{\circ} \mathrm{C}$

- Protein concentrations were measured using the Bradford method and BSA as standard

\subsubsection{Purification of Homo sapiens holo-mNT}

We overexpressed a truncated form of Homo sapiens $(H s) \mathrm{mNT}\left(\mathrm{mNT}_{44-108}\right)$ without its Nterminus mitochondrial anchor, which was therefore restricted to the well-folded part of the protein (Paddock et al., 2007). Codon usage was optimized for its expression in E. coli (GenScript). The open reading frame coding for the fragment M44-T108 was cloned between $N d e \mathrm{I}$ and $X h o \mathrm{I}$ of $\mathrm{pET} 22 \mathrm{~b}(+)$ vector. Using this construct, a His-tag (LEHHHHHH) was added to its C-terminal end without effect on the biochemical properties of the protein.

\section{Columns, buffers and reagents}


- HiTrap Chelating HP 5 mL and Superdex 75 HiLoad 16/60 (GE Healthcare)

- Lysis Buffer: $50 \mathrm{mM} \mathrm{NaPO}_{4} \mathrm{pH} 8.0,500 \mathrm{mM} \mathrm{NaCl}, 15 \%$ glycerol

- Buffer A: $50 \mathrm{mM} \mathrm{NaPO}_{4} \mathrm{pH} 8.0,500 \mathrm{mM} \mathrm{NaCl}, 10 \mathrm{mM}$ imidazole

- Buffer B: 50 mM NaPO 4 pH 8.0, $500 \mathrm{mM} \mathrm{NaCl}, 500 \mathrm{mM}$ imidazole

- Buffer C: $50 \mathrm{mM} \mathrm{NaPO}_{4} \mathrm{pH} 8.0,50 \mathrm{mM} \mathrm{NaCl}$

Procedures $\beta$-Mercaptoethanol cannot be used because it increases cluster degradation. The purification is performed in phosphate buffer for increased protein stability.

(1) Grow $3 \mathrm{~L}$ of LB culture of $E$. coli transformed by the plasmid with $100 \mathrm{mg} / \mathrm{L}$ ampicillin at $37^{\circ} \mathrm{C}$ with an agitation of $150 \mathrm{rpm}$. Three hours later, add $500 \mu \mathrm{M} \mathrm{FeCl}$ and decrease the temperature to $20^{\circ} \mathrm{C}$. When the optical density at $600 \mathrm{~nm}$ reaches 0.7 , add $0.5 \mathrm{mM}$ IPTG. Twenty hours after, centrifuge the cells at 5,000 rpm for $15 \mathrm{~min}$. For nuclear magnetic resonance (NMR) studies, $\mathrm{mNT}_{44-108}$ is expressed in $\mathrm{M} 9$ minimal medium enriched with $0.001 \%$ thiamine- $\mathrm{HCl}$ and $10 \mu \mathrm{M} \mathrm{FeCl}_{3}$ and supplemented with $1 \mathrm{~g} / \mathrm{L}$ of ${ }^{15} \mathrm{NH}_{4} \mathrm{Cl}$ and $4 \mathrm{~g} / \mathrm{L}$ of $\left[{ }^{13} \mathrm{C}\right] \mathrm{D}$-glucose as the sole nitrogen and carbon sources, respectively.

(2) Resuspend the cells on ice in at least $100 \mathrm{~mL}$ Lysis Buffer containing one tablet of protease inhibitors and disrupt them using the cell disruptor. Pass the sample through the cell disruptor until it is no longer viscous (at least three times).

(3) Centrifuge the cell lysate for one hour at $4{ }^{\circ} \mathrm{C}$ and $40,000 \mathrm{rpm}$. Keep the slightly red supernatant.

(4) Equilibrate the HiTrap Chelating HP column with Buffer A, which contains $10 \mathrm{mM}$ imidazole and $500 \mathrm{mM} \mathrm{NaCl}$ to limit non-specific interactions. Load the supernatant on the column then wash it with Buffer A until stable low absorbance is reached. Apply a 30-mL linear gradient between Buffer A and Buffer B at $1 \mathrm{~mL} / \mathrm{min}$.

(5) Pool the red fractions containing mNT (around 40\% Buffer B) and concentrate them down to $2 \mathrm{~mL}$. 
(6) Equilibrate the Superdex 75 HiLoad 16/60 column with Buffer C. Load the proteins and run the column with Buffer C. Apo-mNT will be eluted before the holo-form (50 and $70 \mathrm{~mL}$, respectively).

(7) Check the purity of the colored fractions on $16 \%$ SDS-PAGE gels. Then, analyze the fractions of interest on a $12 \%$ native PAGE gel to check the absence of apo-mNT. Pool pure holo-mNT fractions and concentrate them down to no more than $2 \mathrm{mM}$ to avoid aggregation. Freeze in dry ice and store at $-80^{\circ} \mathrm{C}$. We obtain roughly $12 \mathrm{mg}$ of pure holo-mNT per liter of LB culture.

\subsubsection{Purification of $E$. coli holo-FDX}

E. coli FDX is overexpressed without a tag using the pET21a-FDX construct (Nakamura, Saeki, \& Takahashi, 1999).

\section{Columns and buffers}

- $5 \mathrm{~mL}$ HiTrap DEAE Sepharose FF, Superdex 75 HiLoad 16/60, and $1 \mathrm{~mL}$ MonoQ columns (GE Healthcare)

- Buffer D: 50 mM Tris-HCl pH 7.2, 30 mM NaCl, 0.2 mM EDTA

- Buffer E: 50 mM Tris-HCl pH 7.2, $1 \mathrm{M} \mathrm{NaCl}, 0.2$ mM EDTA

- $\quad$ Buffer F: 50 mM Tris-HCl pH 7.2, 0.1 M NaCl, 0.2 mM EDTA

- Buffer G: 50 mM Tris-HCl pH 7.2, 25 mM NaCl, 0.1 mM EDTA

- $\quad$ Buffer H: 50 mM Tris-HCl pH 7.2, $1 \mathrm{M} \mathrm{NaCl}, 0.1$ mM EDTA

\section{Procedures}

Add $10 \mathrm{mM} \beta$-mercaptoethanol to all buffers just before use.

(1) Grow 6 L of LB culture of E. coli transformed with pET21a-FDX supplemented with 100 $\mathrm{mg} / \mathrm{L}$ ampicillin. When the optical density at $600 \mathrm{~nm}$ reaches 0.7 , lower the temperature to 
$18^{\circ} \mathrm{C}$ and add $500 \mu \mathrm{M} \mathrm{FeCl}_{3}$. Forty minutes later, induce protein overexpression by adding 0.5 mM IPTG. After 20 hours, centrifuge the culture.

(2) Cells are resuspended on ice in at least $200 \mathrm{~mL}$ of Buffer D with antiprotease, disrupted using the cell disruptor and then centrifuged as described for $\mathrm{mNT}$.

(3) Equilibrate the HiTrap DEAE Sepharose FF column with Buffer D. Load the cell lysate on the column and wash the column with Buffer D until stable low absorbance is reached. Apply an $80-\mathrm{mL}$ linear gradient between 0 and $40 \%$ Buffer E. Pool and concentrate the red fractions down to $2 \mathrm{~mL}$.

(4) Equilibrate the Superdex 75 HiLoad 16/60 column with Buffer F. Load the concentrated eluate and run the column with Buffer F. The apo-FDX will be eluted before the holo-form. Analyze the colored fractions on 16\% SDS-PAGE, then pool and concentrate them.

(5) Equilibrate the MonoQ column with $93 \%$ Buffer G/7\% Buffer H. Dilute the protein sample at least 4-fold with Buffer $\mathrm{G}$ without $\mathrm{NaCl}$, load it on the column, then wash it with 10 $\mathrm{mL}$ of $93 \%$ Buffer G/7\% Buffer H. Apply a 60 -mL linear gradient from $7 \%$ to $50 \%$ Buffer $\mathrm{H}$. (6) Analyze colored fractions on $16 \%$ SDS-PAGE and on a $16 \%$ native PAGE gel. Pool the holo-FDX fractions and concentrate them. Freeze in dry ice and store at $-80^{\circ} \mathrm{C}$. We obtain $6-7$ mg of pure holo-FDX per liter of culture.

\subsubsection{Preparation of apo-FDX}

\section{Equipment and buffers}

- NAP-5 column (GE Healthcare)

- Centricon $5 \mathrm{kDa}$ (Millipore)

- Exchange Buffer: 50 mM Tris-HCl pH 7.0, 100 mM NaCl

\section{Procedure}


(1) Incubate $450 \mu \mathrm{L}$ of holo-FDX (at roughly $1 \mathrm{mM}$ ) with $10 \mathrm{mM}$ dithiothreitol (DTT), 10 mM EDTA at $80{ }^{\circ} \mathrm{C}$ until the protein becomes colorless, which is an evidence of cluster disassembly (at least $5 \mathrm{~min}$ ).

(2) Equilibrate the NAP-5 column with $10 \mathrm{~mL}$ of Exchange Buffer. Load the protein and elute it with Exchange Buffer. Collect the eluate in $0.5 \mathrm{~mL}$ fractions and check for the presence of protein using the Bradford assay. Pool the fractions containing apo-FDX and concentrate them using a Centricon $5 \mathrm{kDa}$ down to roughly $450 \mu \mathrm{L}$. Aliquot the protein (10 $\mu \mathrm{L}$ fractions), freeze in dry ice and store at $-80^{\circ} \mathrm{C}$.

\subsection{In vitro cluster transfer reaction between holo-mNT and apo-FDX}

For this reaction, holo-mNT is used as Fe-S cluster donor and DTT-reduced apo-FDX (reduction of the cysteines) as recipient. Recently, we showed that only the oxidized cluster can be transferred and that oxygen does not affect the transfer reaction (Golinelli-Cohen et al., 2016). To prevent cluster disassembly in holo-mNT or holo-FDX, we perform the transfer reaction at a slightly acidic $\mathrm{pH}$ (between 6.0 and 6.7 ; the $\mathrm{mNT}$ cluster is too labile at lower $\mathrm{pH}$ under aerobic conditions) and $25^{\circ} \mathrm{C}$ (holo-FDX is not stable enough at higher temperature) to have complete cluster transfer in a few hours. This timescale allows study of the effect of compounds on the transfer with limited change in the compound during the course of the reaction. Finally, we recommend performing the reaction under anaerobic conditions when studying the effect of oxygen-sensitive molecules on the reaction.

\subsubsection{UV-visible absorption spectroscopy}

This method uses the different spectral properties in the visible region $(350-800 \mathrm{~nm})$ of: (1) holo-mNT (maximum absorption at $458 \mathrm{~nm}$ for the oxidized form) and holo-FDX (415 and $458 \mathrm{~nm}$ for the oxidized form) (Figure 2A), (2) the different redox states of the proteins (Figure 2A and B) and (3) the apo- (no absorbance in the visible) and holo-proteins. Cluster 
transfer is monitored by recording the UV-visible absorption spectra of the reaction over time (Figure 2C). Initially, only holo-mNT contributes to the visible part of the spectrum, whereas only holo-FDX contributes when all $\mathrm{mNT}$ clusters have been transferred (Figure 2A). Thus, at intermediate times, the spectrum is a combination of the contribution of both holo-proteins. While this spectroscopic method can easily follow cluster transfer, it is worth mentioning that one drawback is the difficulty of detecting species at low concentrations.

\section{Equipment}

- UV-visible absorption spectrophotometer Cary 100 (Agilent) with a temperature control apparatus. A multicell holder allows multiple reactions to be followed in parallel

- High-precision cell (Hellma Analytics, reference 105-201-QS). This cuvette is adapted to a small reaction volume (roughly $160 \mu \mathrm{L}$ ) with a reasonable background absorbance

- NAP-5 (GE Healthcare), Micro Bio-Spin 6 Columns (Bio-Rad)

\section{Procedure}

(1) If necessary, change the holo-mNT buffer using a NAP-5 column equilibrated with the desired buffer, and proceed as described for the preparation of apo-FDX. If highly concentrated proteins are used, the contribution of protein storage buffers to the reaction is negligible.

(2) Reduce apo-FDX with $5 \mathrm{mM}$ DTT for $30 \mathrm{~min}$ at room temperature. If necessary, remove DTT using a Micro Bio-Spin 6 column.

(3) Mix holo-mNT and reduced apo-FDX together (typically $20 \mu \mathrm{M}$ of each protein) in the desired transfer reaction buffer. Transfer the reaction mixture into the cell and place it in the thermostated spectrophotometer.

(4) Record full spectra between 240 and $900 \mathrm{~nm}$ (every 5 min during $2 \mathrm{~h}$ and then every 15 min, for example) (Figure 2C). 
(5) At the end of the experiment, correct the spectra for baseline variations (for each wavelength, remove the average of the absorbances between 850 and $900 \mathrm{~nm}$ at the measured absorbance)

(6) Calculate and plot the transfer reaction progress R over time (Figure 2C):

$$
\mathrm{R}=\left(\mathrm{R}_{(\mathrm{t})}-\mathrm{R}_{\text {initial }}\right) /\left(\mathrm{R}_{\text {final }}-\mathrm{R}_{\text {initial }}\right)
$$

- $\mathrm{R}_{(\mathrm{t})}$, ratio between the absorbances at 415 and $458 \mathrm{~nm}$ at time $\mathrm{t}$

- $\mathrm{R}_{\text {initial }}$ and $\mathrm{R}_{\mathrm{final}}, \mathrm{R}$ at the beginning and at the end (when the transfer is complete) of the reaction, respectively.

\subsubsection{Native PAGE}

This method allows separation of the apo- and holo-forms of mNT and FDX and easy quantification of each species even if they are present in low amounts, but it does not give information on the redox state of the clusters (Figure 3).

\section{Equipment}

- $16 \%$ native PAGE gel, loading and electrophoresis buffers (Arndt, Koristka, Bartsch, \& Bachmann, 2012)

- Odyssey Infrared Imaging System (LI-COR)

\section{Procedure}

(1) The reaction mixture is prepared as described previously (see 2.2.1), except that the reaction takes place in a $1.5 \mathrm{~mL}$ centrifuge tube in a thermostated plate.

(2) Aliquots ( $8 \mu \mathrm{L}$ for reactions performed with $20 \mu \mathrm{M}$ proteins) are removed from the reaction mixture at regular times and immediately frozen in dry ice.

(3) When the reaction is complete, add $5 \mathrm{mM}$ DTT to the samples (to obtain thinner bands on gels) and load them on a $16 \%$ native PAGE gel. Run it at $70 \mathrm{~V}$ on ice until elution of the bromophenol blue present in the loading buffer. 
(4) Stain the gel using the highly sensitive Blue Silver staining (Candiano et al., 2004).

(5) After destaining, scan the gel using the Odyssey Infrared Imaging System. Quantify each band (Figure 3) using LI-COR Odyssey software, calculate the ratio [holo-FDX]/[Total FDX] and plot it over time.

\subsubsection{Nuclear magnetic resonance spectroscopy}

1D and multi-dimensional NMR techniques allow the direct and real-time observation and quantification of the various states of $\mathrm{mNT}$ and FDX in a single experiment. Here, we use ${ }^{15} \mathrm{~N}$ labeled holo- $\mathrm{mNT}_{(44-108)}$ and apo-FDX at natural abundance. Each $\mathrm{mNT}$ state gives rise to a distinct ${ }^{15} \mathrm{~N}$ HSQC spectrum, and their relative proportions can be assessed from cross-peak intensity. The ${ }^{15} \mathrm{~N}$ HSQC spectra of holo-mNT in its oxidized or reduced states are very similar and well dispersed, indicating a well-folded protein. Nevertheless, the ${ }^{1} \mathrm{H} /{ }^{15} \mathrm{~N}$ chemical shifts of residues V57, H58 and I102 are distinct in the reduced and oxidized states and are convenient probes of the mNT redox state (see Figure $4 \mathrm{~A}$ ). Upon cluster loss, the ${ }^{15} \mathrm{~N}$ HSQC spectrum shows substantial reduction in ${ }^{1} \mathrm{H}$ spectral dispersion, due to its disordered nature (Ferecatu et al., 2014; Golinelli-Cohen et al., 2016), as shown in figure 4B.

\section{Equipment}

-A high-field NMR spectrometer (at least $600 \mathrm{MHz}$ ) equipped with a triple resonance, preferentially cryogenically cooled, probe.

- For aerobic conditions, standard 3-mm or 5-mm NMR tubes can be used. For anaerobic conditions, we use a 5-mm NMR tube equipped with a controlled atmosphere valve (for example, the NE-CAV5 series from New-Era) and we prepare the sample in a glove box.

\section{Procedure}

(1) Prepare a solution (200 $\mu \mathrm{L}$ for a 3-mm tube, $500 \mu \mathrm{L}$ for a $5-\mathrm{mm}$ tube) of $50-250 \mu \mathrm{M}{ }^{15} \mathrm{~N}$ labeled holo-mNT in the required reaction buffer with 95\% / 5\% $\mathrm{H}_{2} \mathrm{O} / \mathrm{D}_{2} \mathrm{O}$. 
(2) Check the initial redox state of mNT by transferring the solution to the NMR tube and collect reference NMR spectra including the water-suppressed ${ }^{15} \mathrm{~N}$-decoupled ${ }^{1} \mathrm{H}$ spectrum, water-suppressed ${ }^{15} \mathrm{~N}$-filtered ${ }^{1} \mathrm{H}$ spectrum and $2 \mathrm{D}{ }^{15} \mathrm{~N}$ SOFAST-HMQC (Schanda \& Brutscher, 2005; Schanda, Kupce, \& Brutscher, 2005).

(3) Prepare a stock solution of 1-2 mM apo-FDX in $50 \mathrm{mM}$ Tris- $\mathrm{HCl} \mathrm{pH} 8.0100 \mathrm{mM} \mathrm{NaCl}$ $95 \% / 5 \% \mathrm{H}_{2} \mathrm{O} / \mathrm{D}_{2} \mathrm{O}$. Treat apo-FDX with $5 \mathrm{mM}$ DTT for $30 \mathrm{~min}$ to ensure free thiols. If required, excess DTT can be removed using Micro Bio-Spin 6.

(4) Add the required volume of apo-FDX to the mNT sample to achieve the expected mNT/apo-FDX molar ratio and transfer the reaction mixture into the NMR tube. This operation represents time $=0 \mathrm{~h}$ of the reaction.

(5) Collect NMR spectra including the water-suppressed ${ }^{15} \mathrm{~N}$-decoupled ${ }^{1} \mathrm{H}$ spectrum and 2D ${ }^{15} \mathrm{~N}$ SOFAST-HMQC. The reaction rate being rather slow, a series of NMR experiments can last up to $15 \mathrm{~min}$ and be repeated as long as the reaction is not complete.

(6) The progress of the reaction can be followed by monitoring peak intensity variations in the $2 \mathrm{D}{ }^{15} \mathrm{~N}$ SOFAST-HMQC for signals specific to the three mNT states. For the holo-mNT states, peak intensities can be normalized to the initial intensities, assuming that reduced and oxidized states have similar relaxation properties. The apo-mNT is highly dynamic and normalization can be done using intensities at the end of the reaction when holo-mNT has been completely converted into apo-mNT (Figure 4C). The water-suppressed ${ }^{15} \mathrm{~N}$ decoupled ${ }^{1} \mathrm{H}$ spectra contain contributions from the side-chain of the single tryptophan residue (W77) in the apo- (at $10.08 \mathrm{ppm}$ ) and holo-FDX (at $10.02 \mathrm{ppm}$ ) forms that can be used to estimate the population of FDX forms.

\section{Identification of a physiological recipient of the mNT cluster}

A physiological recipient of the mNT cluster has to have the following characteristics: (1) it 
has to be cytosolic (localization of mNT cluster); (2) its apo-form should not be degraded in living cells; (3) its cluster has to be partially or totally disassembled by stress. Considering all these conditions, the first candidate recipient we have identified is cytosolic aconitase/IRP1 (Ferecatu et al., 2014). In mammals, this bifunctional protein readily commutes from a [4Fe4S]-containing form (aconitase activity) to an apo-form (RNA-binding activity) upon exposure to $\mathrm{NO}$ or $\mathrm{H}_{2} \mathrm{O}_{2}$ (Pantopoulos \& Hentze, 1995; Soum \& Drapier, 2003). Interestingly, IRP1 can recycle into cytosolic aconitase after nitrosative stress involving energized mitochondria (Bouton, Chauveau, Lazereg, \& Drapier, 2002). This part will be dedicated to the methods we used to identify and characterize IRP1 as a physiological partner of mNT after nitrosative damage of its cluster.

\subsection{In vitro studies}

The first step is to check if holo-mNT can transfer in vitro its cluster to IRP1, which has been obtained from cytosolic aconitase exposed to nitrosative stress leading to complete Fe-S cluster disassembly (Figure 5).

\section{General considerations}

- The disassembly of the cytosolic aconitase cluster was performed by treatment of the protein using a diazeniumdiolate NO-donor, diethylamine (DEA) NONOate. This donor has a half-life of roughly $2 \mathrm{~min}$ at room temperature and neutral pH (Soum \& Drapier, 2003).

- The insertion of a functional [4Fe-4S] cluster into IRP1 is followed by measurement of the aconitase activity of the reaction. UV-visible absorption spectroscopy (poor absorption of the $[4 \mathrm{Fe}-4 \mathrm{~S}]$ cluster compared to the $[2 \mathrm{Fe}-2 \mathrm{~S}]$ cluster of $\mathrm{mNT}$ ) and native gels (no difference in migration between the cytosolic aconitase and IRP1) cannot be used to monitor the reaction.

- All the steps until the measurement of aconitase activity require a glove box due to the 
high oxygen sensitivity of cytosolic aconitase.

3.1.1. In vitro cluster transfer reaction between holo-mNT and IRP1

\section{Proteins and buffers}

- Human cytosolic aconitase was expressed and purified as described by Brazzolotto et al. (Brazzolotto, Gaillard, Pantopoulos, Hentze, \& Moulis, 1999). Its specific activity was around 20,000 nmole. $\mathrm{min}^{-1} \cdot \mathrm{mg}^{-1}$

- Purified holo-mNT $\mathrm{m}_{4-108}:$ see 2.1.1

- Disassembled mNT: Incubate holo-mNT in Transfer Buffer at $65^{\circ} \mathrm{C}$ for $10 \mathrm{~min}$

-DEA-NONOate (DEA-NO) (Cayman Chemical, Cat. \#82100). Prepare the stock solution in a basic buffer (1 M Bis-Tris Propane $\mathrm{pH} 9.0$, for example)

- Buffer A: 20 mM Hepes pH 7.3, 0.2 mM citrate, 30 mM ammonium acetate

- Buffer B: 10 mM Hepes pH 7.6, 40 mM KCl, 3 mM MgCl 2

- Transfer Buffer: 100 mM Bis-Tris pH 6.2, 100 mM NaCl, 5 mM DTT

\section{Procedure}

(1) Treat $290 \mu \mathrm{M}$ human holo-IRP1 with $7 \mathrm{mM}$ DEA-NO in Buffer A for $1 \mathrm{~h}$ at $29^{\circ} \mathrm{C}$ in a glove box and purify the reaction on a micro Bio-Spin 6 equilibrated with Buffer B. No residual aconitase activity should be detected.

(2) Incubate IRP1 with $5 \mathrm{mM}$ DTT for 30 min at room temperature.

(3) Incubate $100 \mu \mathrm{M}$ holo-mNT at $25^{\circ} \mathrm{C}$ with $25 \mu \mathrm{M}$ IRP1 in Transfer Buffer in a total volume of $20 \mu \mathrm{L}$.

(4) After $30 \mathrm{~min}, 1 \mathrm{~h}$ and $2.5 \mathrm{~h}$, remove $2.5 \mu \mathrm{L}$ aliquots of the reaction mixture to measure aconitase activity (see 3.1.2).

(5) The negative control reaction is performed in parallel using disassembled $\mathrm{mNT}$.

(6) Check the ability of IRP1 to receive a functional cluster by chemical reconstitution using 
$250 \mu \mathrm{M} \mathrm{Na} 2 \mathrm{~S}$ and Mohr's salt for $1 \mathrm{~h}$ at $25^{\circ} \mathrm{C}$ in a glove box. One reaction has to be performed in Buffer B (highest reactivation expected) and one in the Transfer Buffer reaction (positive control of the experiment).

\subsubsection{Measurement of aconitase activity}

Several aconitase assays based on the conversion of cis-aconitate to isocitrate could be routinely used. One is indirect and uses excess isocitrate dehydrogenase, which catalyzes the oxidation of isocitrate into $\alpha$-ketoglutarate, coupled to the reduction of $\mathrm{NADP}^{+}$, which is monitored at $340 \mathrm{~nm}$ (Fansler \& Lowenstein, 1969). Another method uses in-gel detection of aconitase activity after migration of total cell extracts on native gels (differential migration of mitochondrial and cytosolic aconitases) and incubation of the gels in a buffer containing cisaconitic acid and isocitrate dehydrogenase (Tong \& Rouault, 2006). In our case, we directly monitor the disappearance of cis-aconitate at $240 \mathrm{~nm}$ (Drapier \& Hibbs, 1996).

\section{Buffers and chemicals}

- Aconitase Buffer: $100 \mathrm{mM}$ Tris- $\mathrm{HCl}$ pH 7.4 preheated at $37^{\circ} \mathrm{C}$. Flush it with an inert gas as nitrogen before use

- cis-Aconitate solution: $20 \mathrm{mM}$ cis-aconitic acid pH 7.4

\section{Equipment}

-SAFAS Monaco UV-visible spectrophotometer MC 98000 (Monaco) with a temperature controller set at $37^{\circ} \mathrm{C}$.

- High-precision cell (Hellma Analytics, reference 104-QS).

\section{Procedure.}

(1) Add $\left(685-V_{e}\right) \mu L$ of Aconitase Buffer to the cell.

(2) Add $V_{e}$ of the protein to be tested. 
(3) Add $15 \mu \mathrm{L}$ of the cis-aconitate solution. Use a $200 \mu \mathrm{L}$ Pipetman or invert the cell at least three times to mix the reaction. Be careful not to form bubbles.

(4) Start the spectrophotometer and follow the absorbance at $240 \mathrm{~nm}$ for $20 \mathrm{~min}$.

(5) Make a control cell without protein using $685 \mu \mathrm{L}$ of Aconitase Buffer and $15 \mu \mathrm{L}$ of cisaconitate solution. The absorbance of the control reaction should be stable over time.

(6) Calculate the specific activity of aconitase (SA) using the slope of the linear part of the kinetics ( $\Delta \mathrm{A}$, the initial rate). 1 unit corresponds to $1 \mathrm{nmol}$ of substrate consumed per minute. $S A\left(\frac{U}{m g}\right)=\frac{\Delta A * 700}{\epsilon *[c] * V e} ; \varepsilon=3.6 \mathrm{mM}^{-1} \mathrm{~cm}^{-1} ; \mathrm{V}_{\mathrm{e}}$ : volume of the protein to be tested; [c]: protein concentration.

\subsection{In cellulo studies}

For in cellulo studies, we use HeLa cells, a human cell line from cervical cancer easily transfectable by plasmids or siRNA. Cells were exposed to NO challenge, which disrupts the Fe-S cluster of cytosolic aconitase. Then, we followed the kinetics of recovery of cytosolic aconitase activity (3.2.1). To look at the involvement of $\mathrm{mNT}$ in the cluster repair process, we did this experiment with cells depleted or not in mNT using RNAi technology (3.2.2) and we compared the kinetics of activity recovery in the absence and presence of $\mathrm{mNT}$.

\subsubsection{Effect of NO challenge on cytosolic aconitase activity}

In these experiments, cells are treated with an NO donor (3.2.1.1) (Phase 1, Figure 6A), then the NO stress is removed and we monitor the kinetics of cytosolic aconitase activity recovery (3.2.1.2) (Phase 2, Figure 6A).

\subsubsection{NO challenge assay}

\section{Reagents}


- Diethylenetriamine NONOate (DETA-NO) (Cayman Chemical, Cat. \#82120). Prepare a stock solution in basic buffer (1 M Bis-Tris Propane $\mathrm{pH}$ 9.0, for example) or directly in the appropriate cell medium (physiological pH around 7.4).

\section{Procedure}

Day 1. Seed HeLa cells at $3.5 \times 10^{5}$ cells $/ \mathrm{cm}^{2}$ in DMEM containing $4.5 \mathrm{~g} / \mathrm{L}$ glucose and $1 \mathrm{mM}$ stable L-glutamine (Sigma, Cat. \#D0819), supplemented with 1\% penicillin-streptomycin (Sigma, Cat. \#P0781) and 10\% fetal bovine serum (Lonza, Cat. \#DE14-801F). Culture them overnight under $5 \% \mathrm{CO}_{2}$ and humidified atmosphere at $37^{\circ} \mathrm{C}$.

Day 2. Add $250 \mu \mathrm{M}$ DETA-NO in a fresh medium and check the DETA-NO concentration by measuring the absorbance at $252 \mathrm{~nm}\left(\varepsilon=7640 \mathrm{M}^{-1} \mathrm{~cm}^{-1}\right)$ using $100 \mu \mathrm{L}$ of cell medium in 900 $\mu \mathrm{L}$ of distilled water. The absorbance should be around 0.4 (0.2 in the absence of DETA-NO). Add the medium to the cells and incubate them for $16 \mathrm{~h}$.

Day 3. Remove the media, wash the cells twice with medium (the absorbance at $252 \mathrm{~nm}$ should be at 0.2 ), add fresh cell culture medium ( $\mathrm{t}=0$ of the kinetics of aconitase recovery) and then incubate them further (for $1 \mathrm{~h}, 2 \mathrm{~h}, 4 \mathrm{~h}, 6 \mathrm{~h}, 8 \mathrm{~h}$, for example) at $37^{\circ} \mathrm{C}$.

3.2.1.2. Preparation of mitochondria-enriched fractions and cytosolic extracts

\section{General considerations}

- Protein concentrations are measured using the BCA assay (Smith et al., 1985).

\section{Equipment}

- Beckman Coulter LE80K Ultracentrifuge with 70Ti rotor

- $10 \mathrm{~mL}$ thick wall polycarbonate tubes (Beckman, Cat. \# 355640)

\section{Buffers and reagents}


- Buffer A: $0.25 \mathrm{M}$ sucrose, $100 \mathrm{mM}$ HEPES, pH 7.4, 1/200 (v/v) protease inhibitors (Sigma, Cat. \#P8340)

- Digitonin (Merck Millipore, Cat. \#300410) 1\% solution in DMSO stored in dark at room temperature

- Trypan blue 0.4\% (Sigma, Cat. \#93595)

- Buffer B: 100 mM Tris-HCl, pH 7.5, 0.5\% Triton X-100, 1/200 (v/v) protease inhibitors

\section{Procedure}

(1) At the desired time, remove the media and wash the cells twice with cold PBS buffer. Keep cells on ice throughout.

(2) Harvest cells directly in cold Buffer A. Add digitonin (cell permeabilization) at a final percentage of $0.007 \%$, mix gently several times for $15 \mathrm{~min}$ on ice.

(3) Check the permeabilization of cell membranes by staining an aliquot with trypan blue (v/v) and estimate the percentage of permeabilized (blue) cells under a photonic microscope. If less than $90 \%$ of the cells are permeabilized, continue the incubation.

(4) Centrifuge the cell lysate at $10,000 \times g$ for $10 \mathrm{~min}$ at $4^{\circ} \mathrm{C}$ then separate the mitochondriaenriched fractions (pellet, see step 6) from the cytosolic fractions (supernatant, see step 5).

(5) Ultracentrifuge the resulting supernatant at $100,000 \times g$ for $1 \mathrm{~h}$ at $4^{\circ} \mathrm{C}$ in order to remove cell particles. Recover the supernatant (pure cytosol), determine the protein concentration, measure the cytosolic aconitase activity using $50 \mu \mathrm{g}$ of protein (see 3.1.2), calculate the specific activities and plot them over time.

(6) Wash the mitochondria-enriched pellets with cold Buffer A twice and lyse the pellets with degassed Buffer B (usually with $80-100 \mu \mathrm{L}$, depending on the size of the pellet) and incubate 
for $5 \mathrm{~min}$ on ice. Centrifuge at $10,000 \times g$ for $5 \mathrm{~min}$ at $4^{\circ} \mathrm{C}$, recover the supernatant and measure immediately the mitochondrial aconitase activity using $15 \mu \mathrm{L}$ of the mitochondriaenriched fraction (see 3.1.2) and degassed buffer. The mitochondrial aconitase is particularly oxygen-sensitive, therefore mitochondria lysis and enzymatic activity measurements have to be performed under an anaerobic atmosphere using buffers flushed with nitrogen gas.

(7) Measure protein concentration and calculate the specific activities and plot them over time.

Notes

- Keep one dish untreated to measure the specific activity of cytosolic aconitase in control cytosolic extract (roughly $20 \mathrm{U} / \mathrm{mg}$ with HeLa cells). Just after NO stress relief, the activity should be very low (1-2 U/mg).

- NO challenge should not affect the cytosolic aconitase protein level (Figure 6C). We recommend checking it by immunoblotting using standard procedures. Load $40 \mu \mathrm{g}$ of protein extracts on an $8 \%$ reducing SDS-PAGE gel, transfer the proteins onto a membrane (Immobilon PVDF $0.45 \mu \mathrm{m}$, Millipore) and use specific antibodies against IRP1 (from AgroBio, for example) and mitochondrial aconitase.

3.2.2. Involvement of $\mathrm{mNT}$ in the Fe-S repair of cytosolic aconitase after nitrosative stress To check the involvement of mNT in a repair pathway of the cytosolic aconitase cluster after nitrosative stress, we compare the aconitase activity recovery kinetics after NO challenge in HeLa cells with and without siRNA depletion of mNT. In the absence of $\mathrm{mNT}$, slower recovery of aconitase activity indicates involvement of $\mathrm{mNT}$ in the repair pathway (Figure 6B).

\section{General considerations}


- In order to optimize endogenous gene silencing, a range of siRNA duplex concentrations ( $1 \mathrm{nM}$ to $20 \mathrm{nM})$ and different volumes of the transfection reagent (30 to 50 $\mu \mathrm{L}$ for a $100 \mathrm{~mm}$-diameter dish) should be tested beforehand. In the following protocol, we specify the optimized concentrations we use to deplete mNT in HeLa cells.

- At the end of the reaction, check by immunoblot the level of mNT depletion in the mitochondrial extracts (Figure 6C).

\section{Reagents}

- $\quad$ siRNA duplexes (Life Technologies): CISD1 (mNT-0, Cat. \#s31650; mNT-1, Cat. \#s31651), negative control (NC, Cat. \#4390843).

- INTERFERin ${ }^{\mathrm{TM}}$ Transfection Reagent (Polyplus Transfection, Ozyme Cat. \#409-10)

\section{Procedure}

Day 1. Seed cells in a $100 \mathrm{~mm}$ Petri dish to reach approximately $30 \%$ confluence at the time of transfection $\left(3.5 \times 10^{5}\right.$ cells $/ \mathrm{cm}^{2}$ for $\mathrm{HeLa}$ cells) and incubate under $5 \% \mathrm{CO}_{2}$ and humidified atmosphere at $37^{\circ} \mathrm{C}$.

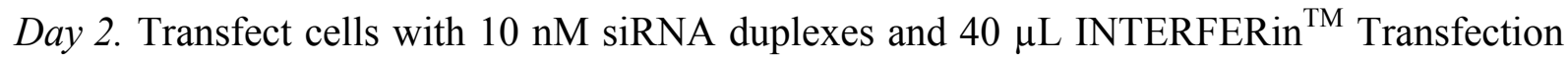
Reagent (the presence of serum and penicillin-streptomycin is not an impediment). Incubate the plate at $37^{\circ} \mathrm{C}$. After $5 \mathrm{~h}$, change the medium to ensure lower toxicity.

Day 3. Proceed to an NO challenge (see 3.2.1.1).

\subsection{Partner protein abundance in mammalian tissues}

In the previous part, the involvement of $\mathrm{mNT}$ in the repair of the cytosolic aconitase was proved using cultured cell lines. To definitively demonstrate that both proteins are partners in mammals, it is necessary to check that they can be both found in at least one common tissue. Thus, we looked at the profile of expression of $\mathrm{mNT}$ and IRP1 in different mouse tissues by 
immunoblotting. Neither is ubiquitous, but they are both well expressed in several tissues, including kidney, liver, heart and brain (Figure 7).

\section{Equipment}

- Sonicator ultrasonic processor XL (Misonix Incorporated). Use it at position 7.

\section{Reagents}

- Transfer Buffer: $12.5 \mathrm{mM}$ Tris-HCl, $96 \mathrm{mM}$ glycine, variable percentage of ethanol

- Buffer A: 50 mM NaCl, 25 mM Tris-HCl pH 7.5, 2 mM EDTA, 0.5\% Triton X-100

- Primary antibodies against IRP1 (Medimabs \#MM-0074, used at a 1/1,000 dilution) and mNT (Eurogentec, antibody raised against the following peptide “CKAVYCRCWRSKKFPF”, used at a 1/2,000 dilution)

- Fluorescent secondary antibodies coupled to IRDye 800CW (LI-COR Biosciences)

- Simply Blue kit (Invitrogen, Life Technologies)

\section{Procedure}

(1) Sonicate $30-100 \mathrm{mg}$ of each tissue in $1 \mathrm{~mL}$ of Buffer A with cocktail protease inhibitor (Sigma, cat\#P8340) $(1 / 200)$ on ice for $15 \mathrm{~s}$ and then centrifuge at $14,000 \times g$ at $4^{\circ} \mathrm{C}$ for 15 $\min$.

(2) Determine the protein content of supernatant using the BCA protein assay.

(3) Separate $10 \mu \mathrm{g}$ of protein extracts on two reducing polyacrylamide SDS-PAGE gels (one $16 \%$ for detection of $\mathrm{mNT}$ and one $8 \%$ for IRP1).

(4) Transfer proteins onto Immobilon-FL (Millipore) membranes for $90 \mathrm{~min}$ at $100 \mathrm{~mA} / \mathrm{gel}$ using Transblot Cell (Life Technology) in Transfer Buffer containing 10\% and 20\% ethanol for IRP1 and mNT detection, respectively. 
(5) Perform immunoblotting using standard procedures. Incubate with primary antibodies overnight at $4^{\circ} \mathrm{C}$. After washing in TBS-T, fluorescent secondary antibodies coupled to LICOR IRDye $800 \mathrm{CW}$ are used at a 1/20,000 dilution (Figure 8).

(6) No protein is expressed at exactly the same level in all tissues and can be used as loading control. Thus, as loading control, perform another SDS-PAGE under the same conditions, but stain the gel using the Simply Blue kit.

\section{CONCLUSIONS}

In this chapter, we described methods to study in vitro Fe-S cluster transfer from holo-mNT to a recipient model, E. coli apo-FDX, and to the first identified physiological recipient, cytosolic aconitase/IRP1 in cellulo and in vivo. More generally, methods described in the first part can be easily adapted to study any protein involved in Fe-S cluster transfer/repair. The second part gives a general scheme to assess physiological Fe-S cluster recipients.

\section{Figure legends}

Figure 1. Scheme summarizing the different steps and methods for studying in vitro Fe-S cluster transfer from holo-mNT to apo-FDX.

Figure 2. UV-visible absorption spectroscopy used to monitor in vitro Fe-S cluster transfer between holo-mNT and apo-FDX. (A) Reaction of cluster transfer between oxidized holo$\mathrm{mNT}$ and DTT-reduced apo-FDX $(20 \mu \mathrm{M}$ each) in $50 \mathrm{mM}$ Bis-Tris $\mathrm{pH} 6.2100 \mathrm{mM} \mathrm{NaCl}$ at $25^{\circ} \mathrm{C}$ under aerobic conditions. At the beginning of the reaction, only oxidized holo-mNT absorbs in the visible part of the spectrum $(350-750 \mathrm{~nm})$, with a maximum at $458 \mathrm{~nm}$. When holo-mNT has completely transferred its cluster, only holo-FDX contributes to the absorption in the visible part of the spectrum, with two maxima at 415 and $458 \mathrm{~nm}$. (B) Visible part of the absorption spectrum of $20 \mu \mathrm{M}$ dithionite-reduced holo-mNT. (C) Kinetics of UV-visible 
absorption spectra of the transfer reaction (only the 380-680 $\mathrm{nm}$ part is shown) (Left panel). The curved arrow indicates the change in absorbance at $415 \mathrm{~nm}$ over time. (Right panel) Reaction progress as a function of time. This research was originally published in Journal of Biological Chemistry. Golinelli-Cohen, MP et al. Redox control of the human iron-sulfur repair protein mitoNEET activity via its iron-sulfur cluster. J. Biol. Chem. 2016; 291: 75837593. (C) the American Society for Biochemistry and Molecular Biology.

Figure 3. Native polyacrylamide gels used to follow in vitro Fe-S cluster transfer between holo-mNT and apo-FDX. (A) Differences in migration between apo-, holo-FDX and holo$\mathrm{mNT}$ on a $16 \%$ reducing native gel. This research was originally published in Journal of Biological Chemistry. Golinelli-Cohen, MP et al. Redox control of the human iron-sulfur repair protein mitoNEET activity via its iron-sulfur cluster. J. Biol. Chem. 2016; 291: 75837593. (C) the American Society for Biochemistry and Molecular Biology. (B) Reaction of cluster transfer between holo-mNT and DTT-reduced apo-FDX $(20 \mu \mathrm{M}$ each $)$ in $50 \mathrm{mM}$ BisTris $\mathrm{pH} 6.2100 \mathrm{mM} \mathrm{NaCl}$ at $25^{\circ} \mathrm{C}$. (Left panel) $\mathrm{mNT}$ was reduced with $2 \mathrm{mM}$ dithionite before starting the reaction performed under anaerobic conditions up to $3 \mathrm{~h}$, then under aerobic conditions. (Right panel) The same reaction is performed under aerobic conditions without reduction of $\mathrm{mNT}$.

Figure 4. NMR fingerprints of mNT. (A) Superimposition of ${ }^{1} \mathrm{H} /{ }^{15} \mathrm{~N}$ correlation spectra of oxidized (black) and reduced (gray or red) holo-mNT in $50 \mathrm{mM}$ Tris- $\mathrm{HCl} \mathrm{pH} 8.0,100 \mathrm{mM}$ $\mathrm{NaCl}$ at $298 \mathrm{~K}$. (B) ${ }^{1} \mathrm{H} /{ }^{15} \mathrm{~N}$ correlation spectrum of apo-mNT in $50 \mathrm{mM}$ Bis-Tris pH 6.2, 100 $\mathrm{mM} \mathrm{NaCl}$ at $298 \mathrm{~K}$. The ${ }^{1} \mathrm{H} /{ }^{15} \mathrm{~N}$ crosspeaks in panels $\mathrm{A}$ and $\mathrm{B}$ are labeled according to their amino acid number. (C) Example of the real-time monitoring of Fe-S cluster transfer from holo-mNT to apo-FDX. In this experiment, reduced holo-mNT was mixed at 1:1 molar ratio with apo-FDX under anaerobiosis. At $\mathrm{t}=0$, the NMR tube was opened and the relative populations of the reduced $\left(\mathrm{mNT}_{\mathrm{red}}\right)$, and oxidized $\left(\mathrm{mNT}_{\mathrm{ox}}\right) \mathrm{mNT}$ and apo-mNT $\left(\mathrm{mNT}_{\text {apo }}\right)$ 
were estimated for the crosspeak intensity in ${ }^{1} \mathrm{H} /{ }^{15} \mathrm{~N}$ correlation spectra, highlighting the cluster transfer from mNT to FDX upon mNT reoxidation. Results presented in panels A and B were originally published in Journal of Biological Chemistry. Golinelli-Cohen, MP et al. Redox control of the human iron-sulfur repair protein mitoNEET activity via its iron-sulfur cluster. J. Biol. Chem. 2016; 291: 7583-7593. (C) the American Society for Biochemistry and Molecular Biology. Panel $\mathrm{C}$ is the quantification of the experiment originally published as Figure 4 in the same publication.

Figure 5. (A) Scheme of the protocol of in vitro reactivation of the activity of cytosolic aconitase by transfer of the mNT cluster. First, purified cytosolic aconitase is treated with DEA-NO under anaerobic conditions (IRP1). Then, IRP1 is incubated with oxidized mNT at $25^{\circ} \mathrm{C}$ under anaerobic conditions at $\mathrm{pH}$ 6.2. (B) Kinetics of aconitase activity after incubation of IRP1 with either $\mathrm{Na}_{2} \mathrm{~S}$ and Mohr's salt, oxidized holo-mNT or disassembled mNT. This research was originally published in Journal of Biological Chemistry. Ferecatu, I et al. The diabetes drug target mitoNEET governs a novel trafficking pathway to rebuild an Fe-S cluster into cytosolic aconitase/iron regulatory protein 1. J. Biol. Chem. 2014; 289: 28070-28086. (C) the American Society for Biochemistry and Molecular Biology.

Figure 6. $\mathrm{mNT}$ is required to restore cytosolic aconitase activity after NO challenge in cellulo. (A) Scheme of the protocol. Cells transfected for $72 \mathrm{~h}$ with mNT or control siRNA were exposed to DETA-NO for $16 \mathrm{~h}$. NO was removed $(\mathrm{t}=0)$ and the cells were incubated further in fresh culture medium for an additional hour. (B) (Left graph) Cytosolic aconitase activity at time $0 \mathrm{~h}$ (phase 1) represented as means $\pm \mathrm{SD}, \mathrm{n}=4, * * \mathrm{p}<0.001$. (Right graph) Relative activities of cytosolic aconitase at $1 \mathrm{~h}$ after NO removal (phase 2). Results are presented as the ratio of cytosolic aconitase recovery for $m N T$-depleted cells over NC cells \pm $\mathrm{SD} \mathrm{n}=4, * \mathrm{p}<0.05$. (C) Immunoblotting of $\mathrm{mNT}$ (mitochondrial fractions) and IRP1 (cytosolic fractions). This research was originally published in Journal of Biological 
Chemistry. Ferecatu, I et al. The diabetes drug target mitoNEET governs a novel trafficking pathway to rebuild an Fe-S cluster into cytosolic aconitase/iron regulatory protein 1. J. Biol. Chem. 2014; 289: 28070-28086. (C) the American Society for Biochemistry and Molecular Biology.

Figure 7. Level of expression of $\mathrm{mNT}$ and IRP1 in different mouse tissues. (A) Immunoblotting against mNT and IRP1. (B) SDS-PAGE gel stained with Simply Blue. (1) brain stem; (2) kidney; (3) lung; (4) liver; (5) muscle; (6) spleen; (7) brain; (8) spinal cord; (9) heart; (10) cerebellum; (11) testis; (12) pancreas.

\section{References}

Arndt, C., Koristka, S., Bartsch, H., \& Bachmann, M. (2012). Native Polyacrylamide Gels. In B. T. Kurien \& R. H. Scofield (Eds.), Protein Electrophoresis: Methods and Protocols (pp. 49-53). Totowa, NJ: Humana Press.

Bouton, C., Chauveau, M. J., Lazereg, S., \& Drapier, J. C. (2002). Recycling of RNA binding iron regulatory protein 1 into an aconitase after nitric oxide removal depends on mitochondrial ATP. J. Biol. Chem., 277(34), 31220-31227.

Brazzolotto, X., Gaillard, J., Pantopoulos, K., Hentze, M. W., \& Moulis, J. M. (1999). Human cytoplasmic aconitase (Iron regulatory protein 1) is converted into its [3Fe-4S] form by hydrogen peroxide in vitro but is not activated for iron-responsive element binding. J. Biol. Chem., 274(31), 21625-21630.

Candiano, G., Bruschi, M., Musante, L., Santucci, L., Ghiggeri, G. M., Carnemolla, B., et al. (2004). Blue silver: a very sensitive colloidal Coomassie G-250 staining for proteome analysis. Electrophoresis, 25(9), 1327-1333.

Colca, J. R., McDonald, W. G., Waldon, D. J., Leone, J. W., Lull, J. M., Bannow, C. A., et al. (2004). Identification of a novel mitochondrial protein ("mitoNEET") crosslinked specifically by a thiazolidinedione photoprobe. Am. J. Physiol. Endocrinol. Metab., 286(2), E252-260.

Drapier, J. C., \& Hibbs, J. B., Jr. (1996). Aconitases: a class of metalloproteins highly sensitive to nitric oxide synthesis. Methods Enzymol., 269, 26-36.

Fansler, B., \& Lowenstein, J. (1969). Aconitase from pig heart. Methods Enzymol., 13, 2630.

Ferecatu, I., Gonçalves, S., Golinelli-Cohen, M.-P., Clémancey, M., Martelli, A., Riquier, S., et al. (2014). The drug diabetes MitoNEET governs a novel trafficking pathway to rebuild an Fe-S cluster into cytosolic aconitase/Iron Regulatory Protein 1. J. Biol. Chem, 289(41), 28070-28086.

Golinelli-Cohen, M. P., Lescop, E., Mons, C., Goncalves, S., Clemancey, M., Santolini, J., et al. (2016). Redox Control of the Human Iron-Sulfur Repair Protein MitoNEET Activity via its Iron-Sulfur Cluster. J. Biol. Chem. , 291(14), 7583-7593. 
Heidrich, H. G., Albracht, S. P., \& Backstrom, D. (1978). Two iron-sulfur centers in mitochondrial outer membranes from beef heart as prepared by free-flow electrophoresis. FEBS Lett, 95(2), 314-318.

Inupakutika, M. A., Sengupta, S., Nechushtai, R., Jennings, P. A., Onuchic, J. N., Azad, R. K., et al. (2017). Phylogenetic analysis of eukaryotic NEET proteins uncovers a link between a key gene duplication event and the evolution of vertebrates. Sci Rep, 7, 42571.

Nakamura, M., Saeki, K., \& Takahashi, Y. (1999). Hyperproduction of recombinant ferredoxins in escherichia coli by coexpression of the ORF1-ORF2-iscS-iscU-iscAhscB-hs cA-fdx-ORF3 gene cluster. J Biochem, 126(1), 10-18.

Paddock, M. L., Wiley, S. E., Axelrod, H. L., Cohen, A. E., Roy, M., Abresch, E. C., et al. (2007). MitoNEET is a uniquely folded 2Fe 2S outer mitochondrial membrane protein stabilized by pioglitazone. Proc. Natl. Acad. Sci. U S A, 104(36), 1434214347.

Pantopoulos, K., \& Hentze, M. W. (1995). Rapid responses to oxidative stress mediated by iron regulatory protein. The EMBO journal, 14(12), 2917-2924.

Schanda, P., \& Brutscher, B. (2005). Very fast two-dimensional NMR spectroscopy for real-time investigation of dynamic events in proteins on the time scale of seconds. J Am Chem Soc, 127(22), 8014-8015.

Schanda, P., Kupce, E., \& Brutscher, B. (2005). SOFAST-HMQC experiments for recording two-dimensional heteronuclear correlation spectra of proteins within a few seconds. J Biomol NMR, 33(4), 199-211.

Smith, P. K., Krohn, R. I., Hermanson, G. T., Mallia, A. K., Gartner, F. H., Provenzano, M. D., et al. (1985). Measurement of protein using bicinchoninic acid. Anal Biochem, 150(1), 76-85.

Soum, E., \& Drapier, J. C. (2003). Nitric oxide and peroxynitrite promote complete disruption of the $[4 \mathrm{Fe}-4 \mathrm{~S}]$ cluster of recombinant human iron regulatory protein 1. J Biol Inorg Chem, 8(1-2), 226-232.

Tamir, S., Paddock, M. L., Darash-Yahana-Baram, M., Holt, S. H., Sohn, Y. S., Agranat, L., et al. (2015). Structure-function analysis of NEET proteins uncovers their role as key regulators of iron and ROS homeostasis in health and disease. Biochim Biophys Acta, 1853, 1294-1315.

Tong, W. H., \& Rouault, T. A. (2006). Functions of mitochondrial ISCU and cytosolic ISCU in mammalian iron-sulfur cluster biogenesis and iron homeostasis. Cell metabolism, 3(3), 199-210.

Wiley, S. E., Murphy, A. N., Ross, S. A., van der Geer, P., \& Dixon, J. E. (2007). MitoNEET is an iron-containing outer mitochondrial membrane protein that regulates oxidative capacity. Proc. Natl. Acad. Sci. U S A, 104(13), 5318-5323.

Zuris, J. A., Harir, Y., Conlan, A. R., Shvartsman, M., Michaeli, D., Tamir, S., et al. (2011). Facile transfer of [2Fe-2S] clusters from the diabetes drug target mitoNEET to an apo-acceptor protein. Proc. Natl. Acad. Sci. U S A, 108(32), 13047-13052. 


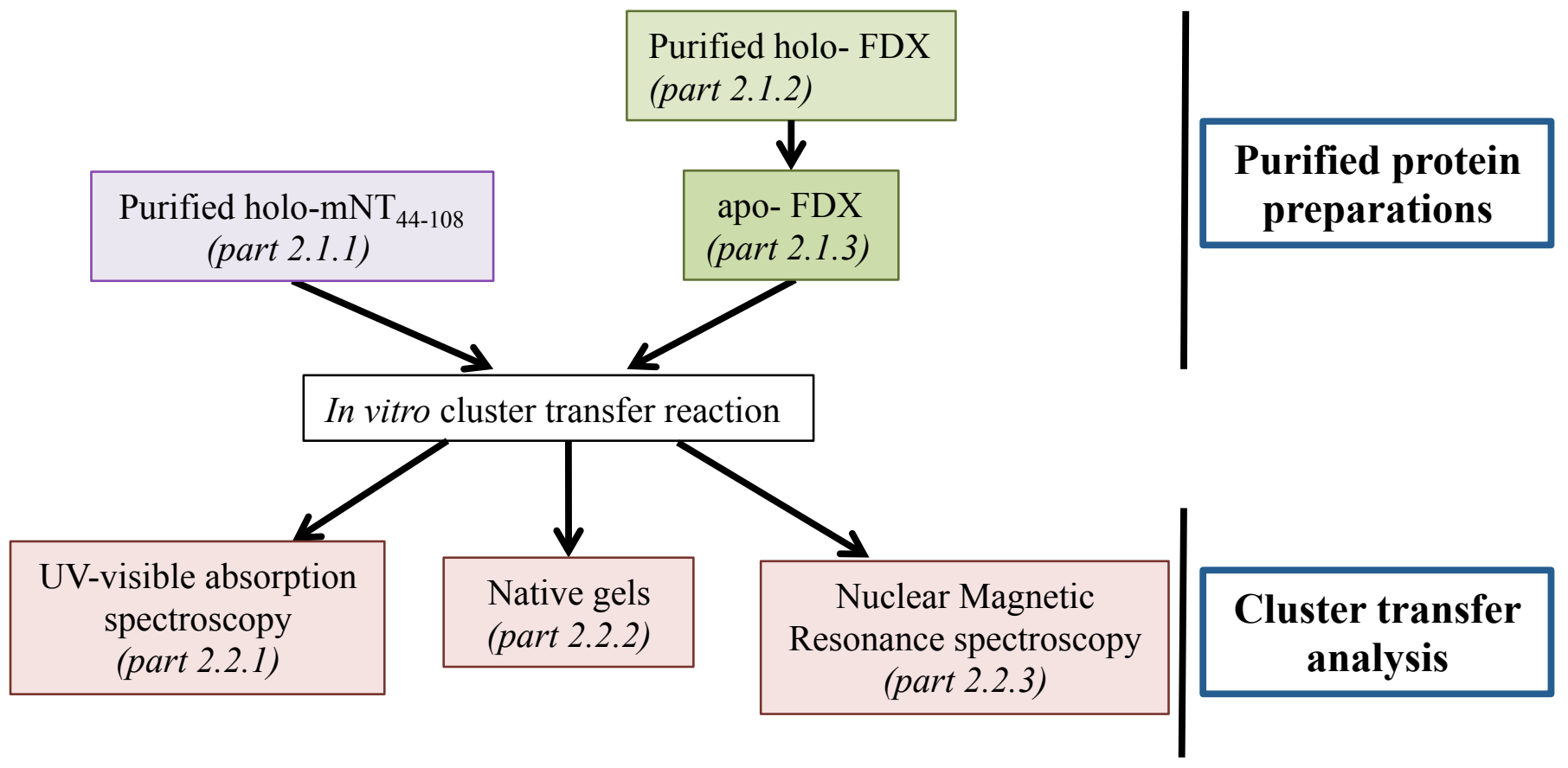

Figure 1. 
(A)

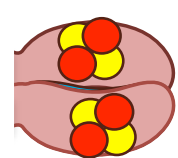

Oxidized

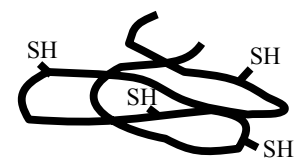

DTT-reduced Holo-mNT ${ }_{44-108}$ Apo-FDX

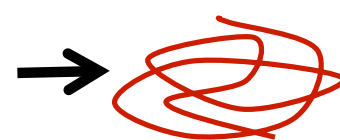

Apo- $\mathrm{mNT}_{44-108}$

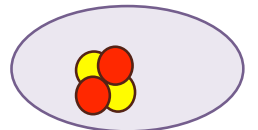

Holo-FDX

(B)

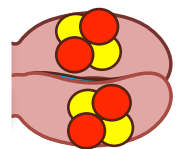

Reduced

Holo-mNT ${ }_{\text {44-108 }}$

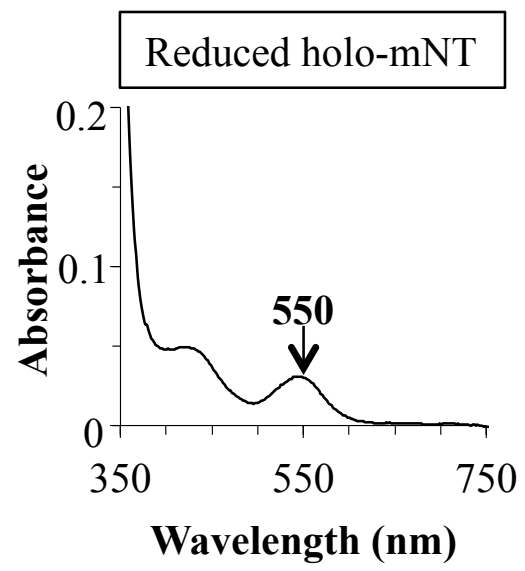

(C)
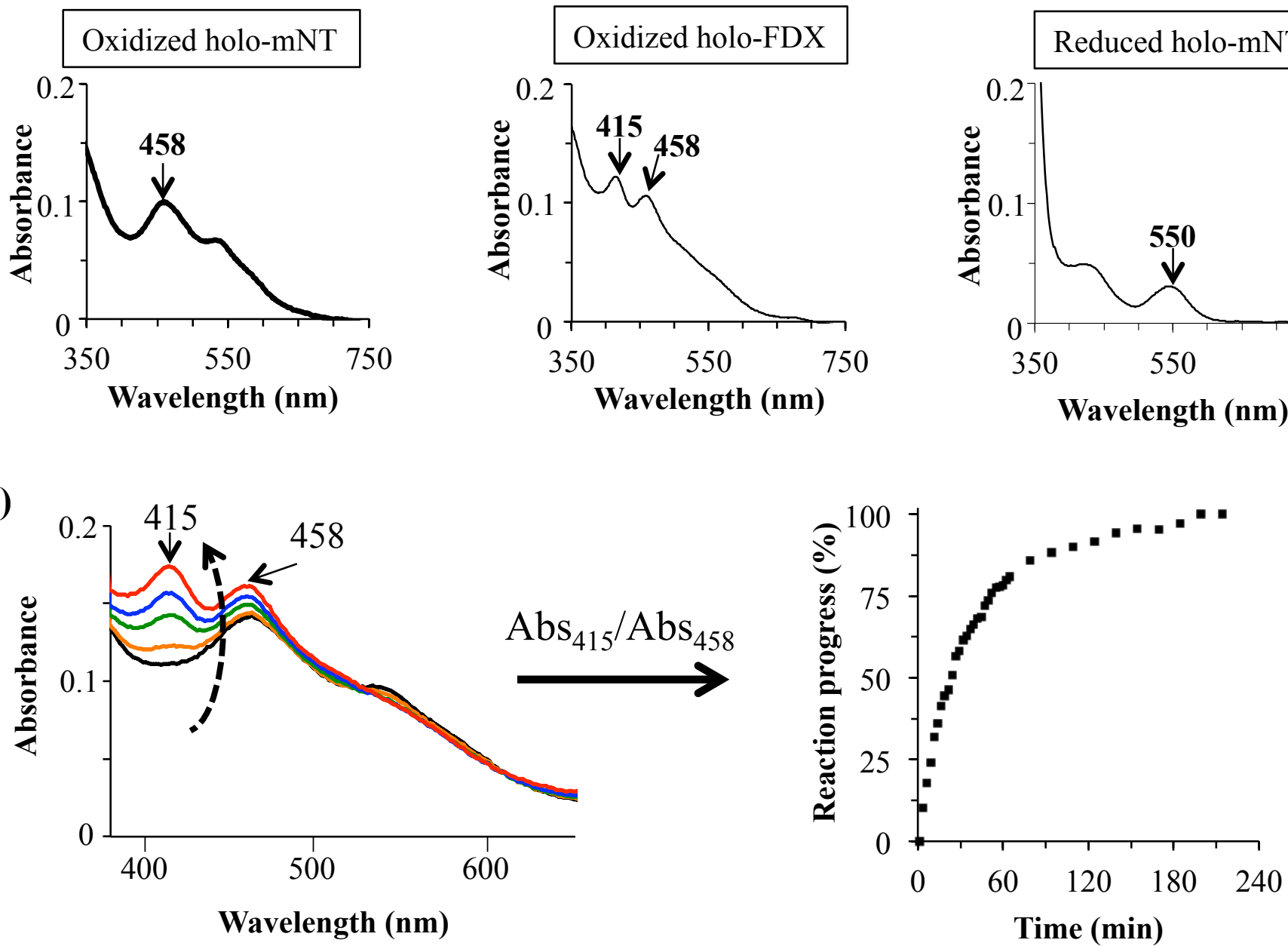

Figure 2. 

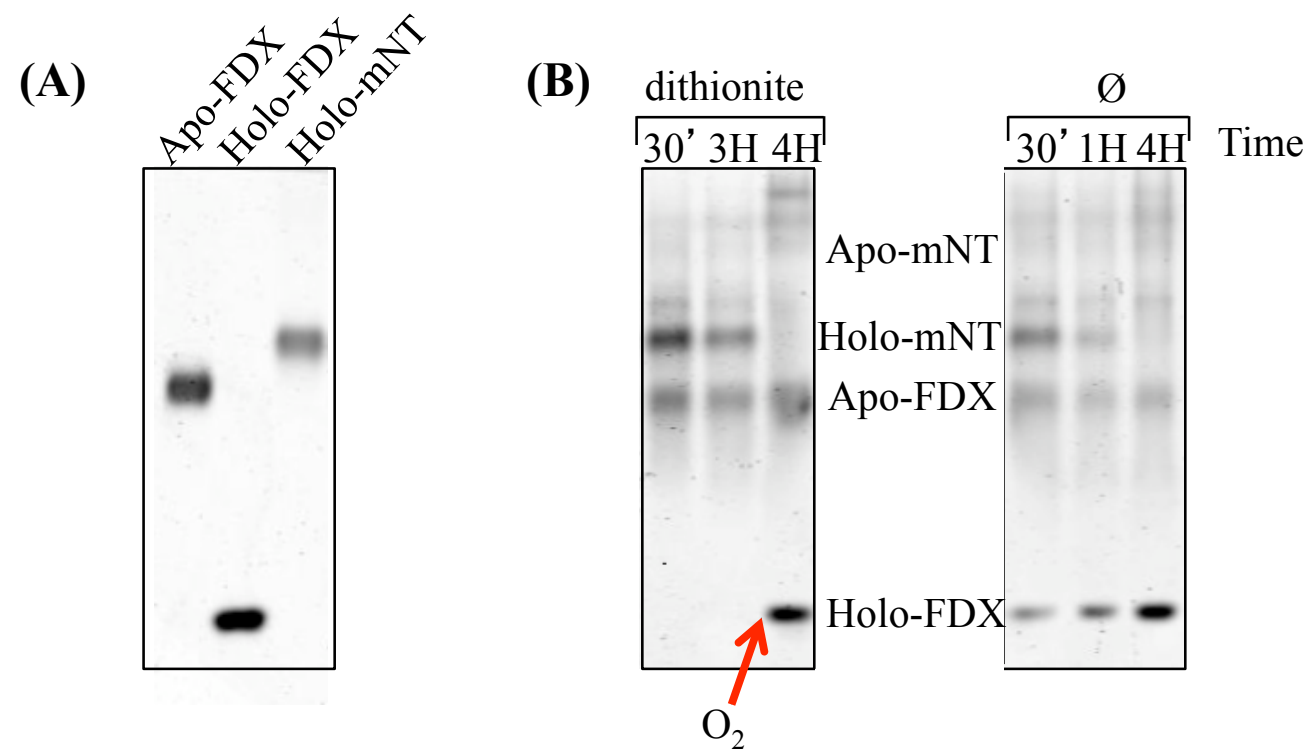

Figure 3. 
A)

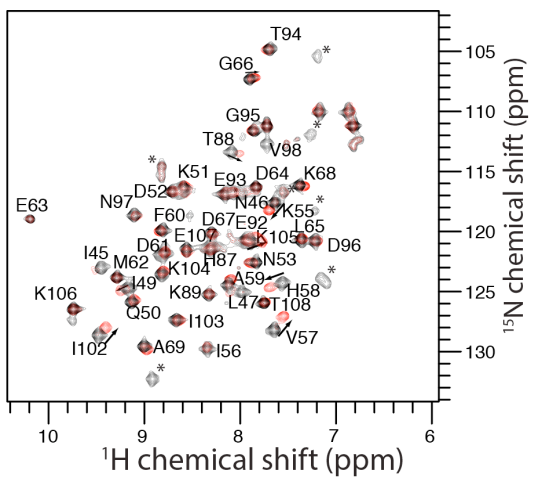

B)

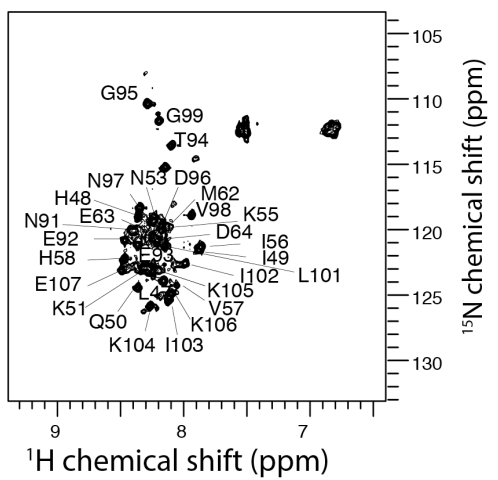

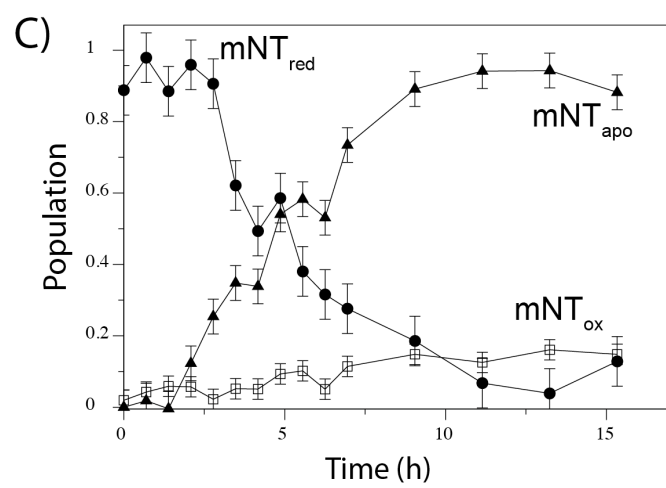

Figure 4. 
(A)

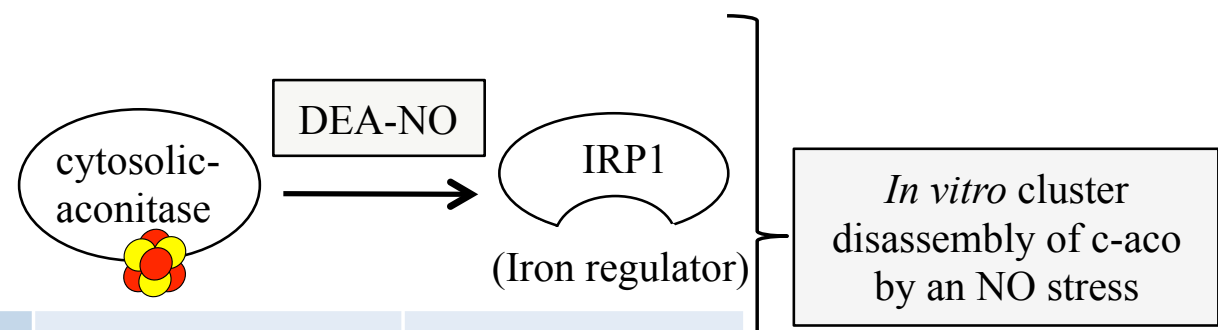

Specific aconitase activity (nmole. $\mathrm{min}^{-1} \cdot \mathrm{mg}^{-1}$ )

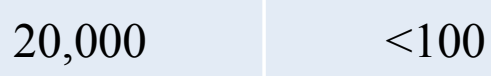

R

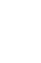

Oxidized holo- $\mathrm{mNT}_{44-108}$

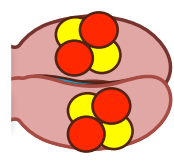

In vitro cluster reassembly of c-aco by $\mathrm{mNT}$

(B)

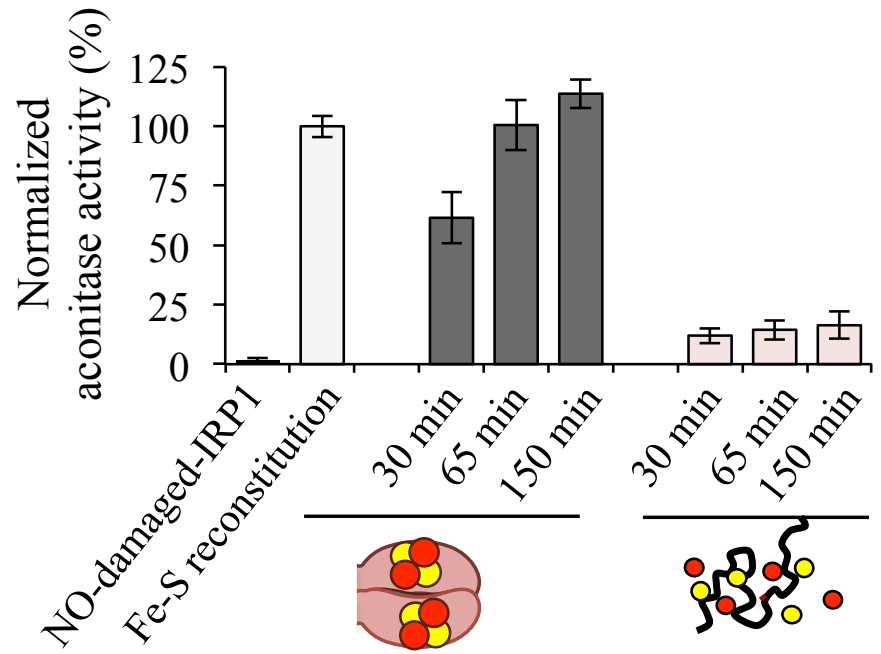

Oxidized holo-mNT Disassembled mNT

Figure 5. 


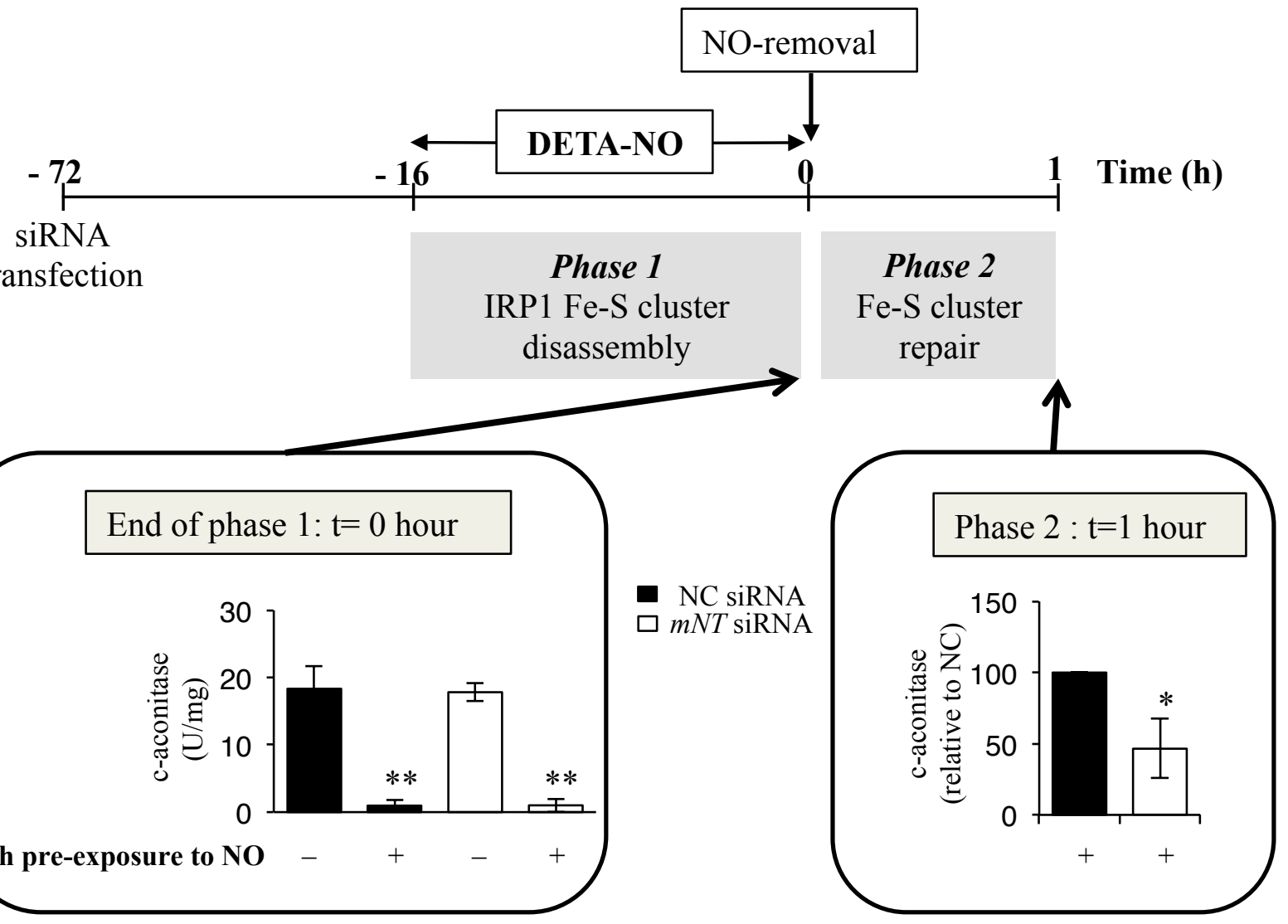

C

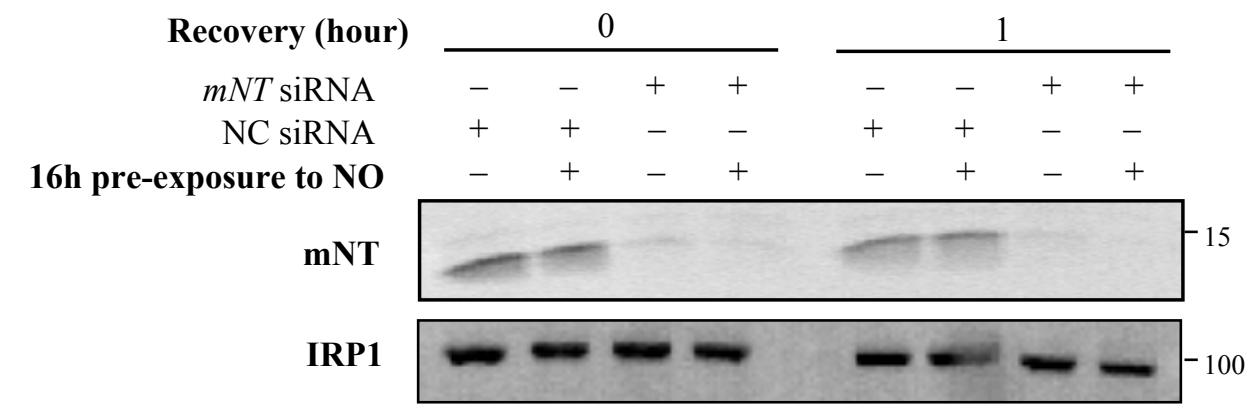

Figure 6. 
(A)

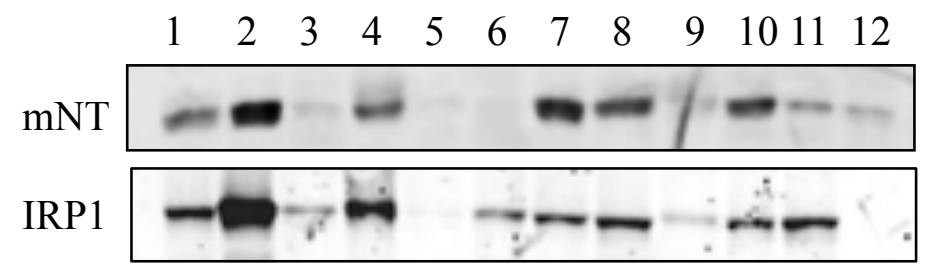

(B)

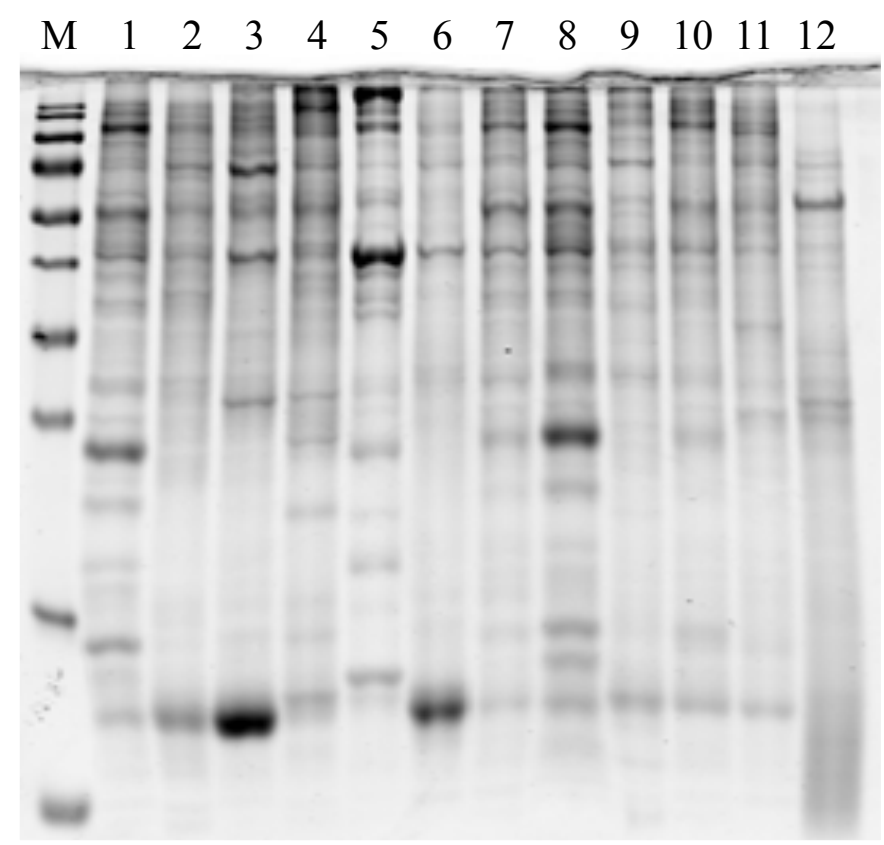

Figure 7. 